\title{
Social Control in Network Communities Analytic Study
}

\author{
Abdullah Ahmed Algarni* \\ Faculty of Arts and Humanities, Department of Sociology and Social Work \\ KAU, Jeddah, Saudi Arabia; abdullah62@gmail.com
}

\begin{abstract}
Background/Objectives: To define the new concept of social control in network communities and to answer the following questions: What is the new social control? What are the methods of this new social control? and how to reach a controlled use of network communities? Methods/Statistical Analysis: The study used the analytic descriptive methodology that is based on the research and study of the new concept of social control and its main patterns from different angles and qualitatively expresses them through studying the literature review of the problem and discussing it. The study categorized the methods of new social control into two major categories: First, official methods of social control, which are set by the society to enforce a kind of purposeful control of its members through guiding rules and instructions in forms of regulatory legislations to be adhered by all society institutions and individual alike; Second, non-official methods of social control, such as individuals' following of societal criteria and values, through the process of socialization. We used 29 references of previous studies. Findings: The study defined the new concept of social control as the collective practices and behaviors of society upon its members to educate them, organize their behaviors or control them in order for their behaviors to be consistent with the prevailing criteria through a group of various methods that lead their behaviors to meet the society expectations, such as methods aim at preserving the growth and sustainability of the society and protecting its structure. To achieve the most suitable control of any given society, different societal bodies of two directions - integrated in roles and results - emerge. The first direction stems from inside, where the individual internally desires to adhere to societal criteria and values. This direction is achieved through proper introduction of individuals to the digital environment, starting from the early childhood to the teenage and continues if the individual uses network communities. The second direction is institutional that is reflected on the set laws and written regulations by official authorities such as the Electronic Transactions Law, and the Cyber Crimes Act. Improvements/Applications: The results of this study are confined to the predetermined goals that it sought to achieve and the questions that it sought to answer. Hence, conducting more studies about social control and their different social dimensions to achieve more generalized results is needed. The researcher recommends better dissemination of laws on the use of network communities as well as more attention to the digital socialization of children and adolescents, thus contributing to the development of active and disciplined members of society in the network communities.
\end{abstract}

Keywords: Digital Communities, Network Society, Social Control

\section{Introduction}

Nowadays, our contemporary world witnesses a few rapid changes in the fields of communication and information technology, which made it a global village where information is transferred to all parts of the world in fractions of a second. Undoubtedly, such changes have its direct impact upon individuals and societal institutions alike. This, in turn, led societies to accept these changes and adapt accordingly in order to make use of its provided

${ }^{*}$ Author for correspondence 
benefits in all fields; as the number of internet users has reached 3.5 billion worldwide, which is $47 \%$ of the total world population ${ }^{1}$.

The new lifestyle that is totally dependent on using the internet with its different forms and applications is a new trend that is of huge revolution in the fields of information technology and digital information where modern technologies became part and parcel of our new life due to what they provide to facilitate our everyday tasks. This huge technological revolution that we are currently witnessing has many positives and negatives for individuals and the whole society as well. Individuals' use of the internet and its different services led to the formation of social communities that arise from the internet and enough number of people continues in their discussions in public for a while, with enough human feelings to form networks of personal relationships in Cyberspace forming what is so-called 'virtual communities'2. Thus, a network community is consisted of media and social networks that form the body of the society and its main structure on different levels: individually and institutionally, which represent the new societal turns in our modern age and contribute to its formation as well 3 .

In fact, people depend nowadays on these network communities to do almost all their everyday tasks; like socializing, exchanging news, knowledge transfer and business practices as well. Using the internet in all fields has led to many benefits in all aspects of life, greatly enhanced many services and truly helped information transformation. The cost of using the internet dropped down since the network communities have emerged. Individuals using the internet seek to properly use it in accordance with ethical rules, considering into account the social and legal controls of each society, which aim at limiting the negative impacts of technology upon society. Due to the need of society for these new technologies, we must make use of them to establish positive principles and values among the members of society, the most important of which are those that depend on social control. They would contribute to avoid the negative impacts of technology upon society through elevating the behavior of individuals in their use of technology in a conscious and disciplined manner.

Social control is one of the most important issues tackled by sociologists because of its direct relation to society organization and the lives of its individuals. However, the most eminent of them is the Arab scholar
Ibn Khaldoun who referred to the social control in a more explicit way stating that humans need a kind of authority that controls their social behavior and the development of cities needs the intervention of the authorities and the Sultan for effective prevention and protection of social institutions. The controlling methods are: religion, law, public morals, common practices, customs and traditions $s^{4}$.

Perhaps, it is necessary to redefine the concept of social control especially with the advent of network communities that have been an integral part of individuals' lives in our modern age, which may lead to a new pattern of social control. Thus, this study aimed primarily at defining the new concept of social control, explaining its methods and how to achieve a safe and proper usage of all software, applications, and websites as well as a disciplined lifestyle within network communities. The study problem is limited to the following questions:

- What is the new social control?

- What are the methods of this new social control?

- How to reach a controlled use of network communities?

In order to answer these questions and to achieve the study objectives, the researcher followed the descriptive methodology, which is detailed and scrutinizing, aiming at a deep vision and thorough analysis to pinpoint the context of the research topic as well as the internal and external factors. The researcher avoided presenting a general overview, instead provided the detailed specific requirements of each point without stating presuppositions and tried to be objective; accordingly, the study followed the analytic descriptive methodology.

\section{Literature Reviews}

The ideas of sociologists in our modern age differed over the concept of social control and its implications. Their definitions of this concept have varied greatly; therefore, different visions of social control have emerged, each vision explains the scholar's point of view and his idea about social control. Among them, the well-known American sociologist Edward A. Ross, who defined it as targeted and purposeful social control, based on the good nature of $\operatorname{man}^{5}$. He believes that human psyche has four instincts: Participation or empathy, tendency to socialize, sense of justice and individual reaction; these instincts 
constitute a social system of man based on the exchange of relations among members of society in a friendly manner.

The more the society develops, the more these instincts fade away and self-interest emerges; thus, society finds it necessary to set more rules to control relationships among its members ${ }^{6}$. These controlling rules increase in developed societies with complicated structures and groups of different backgrounds and various interests. Therefore, there are different causes of social control and its developed methods ${ }^{\underline{7}}$ such as:

- The increased numbers of population and the emergence of new factions

- The feeble natural instincts, and strong self-interests

- The appearance of different groups (economically, culturally, racially,) in the same society

The American sociologist, Stephen Cole, saw society as an indivisible whole whose social structure depends on symbols, patterns, collective levels and values. He believes that social control is a continuous process of society's selfcreation, which means that it is a self-control process, the society controls and is controlled at the same time. Therefore, individuals are not isolated from the social collective thoughts; social control is applied to this social whole and by that social whole, and it appears in both large societies and small groups alike ${ }^{8}$.

Functional constructionists focused on components of social construction and their role in social control. They also focus on the concept of functional balance between social systems and the relationship of these social systems with social control. They consider the social systems as one theoretically connected line; at one of its ends lies social disintegration characterized by disorder and individual inclinations, whereas at the other end lies the strictest social organization characterized by reliance on absolute power; between these both ends there is a large area of tolerance.

Integrated Cultural Theory focuses on the necessity of studying social control depending on certain principles and conditions:

- Social control is not a result of the development of societies, but it existed from early human history since no society can ever exist without controls.

- Social control is a social fact not a method of development.

- There are no conflicts between society and individuals.
- Each type of societies is like a small world consisted of groups of people; thus, social control institutions differ in accordance with groups and institutions.

Indeed, there is a wide discrepancy among sociologists regarding the nature of social control; some related it to human instincts and their positive and/or negative role affecting self-discipline, other sociologists linked it to customs and traditions as the only method of social control, whereas others focused on the important roles of social values to reach self-control. Social control is based on individuals' self-control. Some focus on social systems as methods of social control or setting necessary conditions that should be taken into consideration when studying social control; or as social method and processes to keep individuals from deviating away of social norms and they may be persuasive or sometimes obligatory.

However, these methods that aim at achieving social control are various and very complex; for practices that control the behavior of individuals and work as forces that oblige individuals to comply with social norms vary greatly since each human society has its own controlling methods that organize the individuals' lives and control their behaviors to achieve social control; such as, laws, common practices, customs and traditions. The methods of social control differ in their importance within different societies and in different time and place. In some societies, individuals' methods come first and then laws follow in the second place. In other societies, the opposite is the case. In addition, the wide variety of social control types and their difference among different societies, and throughout different ages, is a complex issue in sociology ${ }^{9}$.

Subsequently, there is no one specific definition of social control methods and no one agreed-at categorization. Some sociologists named them Tools of Social Control and confined them to the following fifteen: Public opinion-law-beliefs-social implicationeducation-traditions-religion of majority-ideals rituals-art-personality-heritage-social values-myths and illusions-ethics ${ }^{10}$.

However, other sociologists classified tools of social control into two major categories:

- Tools necessary to form social order, they include: values, standards, common practices and customs.

- Tools necessary to support such social order, they are in turn set into two groups:

- Social Systems; such as, family, religion, school, economics, science and technology. 
- Social Structures; such as, race, class, primary and secondary groups ${ }^{\underline{11}}$.

Despite the differences in the name of social control methods and their classifications, there is almost a consensus about the importance of such methods. Social Control Methods have been categorized into two main sets:

\subsection{Official Methods of Social Control}

The type of methods established by society to impose a kind of purposeful control upon its members; such as, rules, regulations, guidelines or instructions that are formulated as regulatory legislations to be committed by all institutions and to be followed when drafting societal, political, educational and economic laws. Such official methods are set by authorities that have the right to charge any violators.

\subsection{Non-official Methods of Social Control}

i.e. individuals' adherence to social norms and values through the process of socialization; where the community values of individuals are products of informal social control, which is implicitly practiced by society through specific traditions, norms and customs. In general, individuals absorb their community's values, whether consciously or unconsciously. Informal penalties include shame, ridicule, sarcasm, criticism and disapproval, which can lead the individual to move away from societal norms which are prevailed in their community. In extreme cases, penalties may include social discrimination and exclusion.

Another classification of social control method put them into systems, laws and written regulations set by authorities and official institutions under the title of Direct Social Control on the one hand. On the other hand, there are community's customs, traditions, values and norms under the title of Unconscious Source of Social Control ${ }^{12}$.

Many studies have tackled the concept of social control; for instance, Eric Carleton in his 2015 study ${ }^{13}$ states that it is a term used to indicate the processes which confirm that individuals are in line with community standards. Since interests are diverse within groups, social control mechanisms contribute to the resolution of conflicts between such interests and create a degree of social acceptance and harmony.

Another study by American sociologist Erich Goode and others in $2015^{\frac{14}{4}}$ tried to understand the concept of social control or the efforts exerted to ensure the adjustment of individuals' standards in accordance with social norms. The study emphasized the theory of selfcontrol which explains the nonconformity of individuals to social norms because of lack of self-control. Since all communities distinguish between acceptable behaviors and unacceptable behaviors, all communities have imposed certain rules about what their members can or cannot do. The study finally presented the concept of social order as being protected by social control that is symbolic and cultural as well as natural and physical. The study also categorized the types of social control into formal types and informal ones.

As for the studies which tackled the concept of network communities, in Jacob Van Kokswijk' study in 2010 ${ }^{15}$ considered the network communities as real worlds, concluding that social control in network communities is necessary to keep a prevailing amicable atmosphere within online communities. In addition, the study raised the following questions: If there is a kind of social control for many years now in cyberspace, does this mean that laws are not necessary? Then, why many people are still calling for the need for internet police that should keep order throughout the internet? And why we should put new rules for network communities if there are already many rules? Are social agreements and social supervision sufficient? The study also showed that most people find that the fundamental principle of using the internet assumes that all people know the related laws thoroughly; most people see that self-discipline in network communities is not enough, they see the necessity of governmental intervention in cases of serious abuse or criminal cases. Balance between internal and external measures could be achieved through shared efforts by all concerned parties to draft joint regulations, where supervision, maintaining order and settling disputes and misconduct are organized openly. If the costs of learning and using the law are very high, then governments should amend the law; otherwise, citizens will ignore it anyway. These high costs, therefore, serve as pretexts for negotiation instead of complex government solutions to online social conflicts as well as property rights.

In 2017, Nigel Stanger and others listed a number of questions in their study ${ }^{16}$ about how regional cultural factors influence participation in network communities with the global growth of social media platforms; focusing on Saudi youth users for some of the most popular platforms; such as, Instagram, Facebook and Snapchat. 
This study used the cultural dimensions to evaluate how cultural and religious factors shape and restrict social media relationships, using interviews, questionnaires and analysis of personal profiles. The study also discussed some of the interrelated cultural and religious factors that affect how young Saudis are negotiating their use of social media developed in completely different cultural contexts. In addition, the study highlighted gender concerns and the strong impact of the social community on how these sites are used and how users manage the information they share as Saudi youth users.

The results of the study showed that attitudes and behavioral dynamics among Saudi social media users reflect the values and standards of their national and religious culture. This includes expectations of modesty, especially for young women and the strong influence of community and family leaders on an individual's behavior and how they decide whether others should share personal information or not. It has also showed how deep the cultural influences are on Saudi users; for they engage in very limited and tactical social participation behaviors, so that they can comply with the standards and values of their communities and avoid penalties from social and local leaders. The study has also found that young people are responsive to these social structures if they engage in network communities, strongly influenced by these pressures from the standards and values of their societies.

The 2018-study of Abdullah Algarni ${ }^{17}$ explained the concept of digital upbringing and pinpointed the extent of parents' participation and education of adolescents to use social networks as a pattern of modern socialization or digital upbringing. The study examined the concept of digital upbringing using the analytic descriptive methodology. The research sample consisted of 458 of parents of adolescents using social media networks. The study phrased the definition of digital upbringing as educating individuals the proper behaviors in multiple uses of technology; such as, electronic exchange of information, electronic participation in network communities and buying and selling goods via internet. So that such uses would be proper and responsible, to satisfy different needs of individuals, in a way that does not violate the customs and traditions of the community or expose them to any legal accountability. This is not confined to education only, but also the involvement of parents' participation with their children in their network communities and the follow-up of their accounts in social networks or their various digital activities and promoting positive behavior with support and encouragement.

\section{Research Problem}

Nowadays, our contemporary world witnesses several rapid changes in the fields of communication and information technology, which made it a global village where information is transferred to all parts of the world in fractions of a second. There is no doubt that such changes have its direct impact upon individuals and societal institutions alike. This, in turn, led societies to accept these changes and adapt accordingly to make use of the provided benefits in all fields. Network communities have privileges over local communities; such as, flexibility and the collapse of the idea of the reference group in its traditional sense; since a network community is not determined by geography or tribe, but by common interests. One can communicate with others through social networking sites, forums, newsgroups and other electronic media and environments in one's car, home or office at any time if one has a computer or a smartphone and internet access.

Due to the fact that geography no longer plays a role in shaping network communities, one can find someone to communicate with around the clock. Another main feature of network community is that they are based on freedom of choice, there are no obligations.

Nothing compels one to accept the friendship of another, nor to reply to an email or to comment on a tweet or a post. It is also noteworthy that not only national identities are forged, but also personal identities as well; because members of network communities often use nicknames and faces that are not their real faces. Some of them use more than one account and more than one identity according to each goals; identity for coworkers, another for friends and other identities for other purposes ${ }^{18}$.

The global acceleration in the use of network communities leads us to the fact that every user would behave in a manner that is consistent with the standards of their society and in a way that has no legal responsibility consequences; in other words, the need for a new pattern of social control in these network communities. Hence the importance of this current study to enrich the human knowledge through defining the new concept of social control and the methods of this new social control 
and then how to reach a controlled use of network communities. Accordingly, this study sheds light on the new social control through trying to find answers of the following questions:

What is the new social control?

What are the methods of this new social control?

How to reach a controlled use of network communities?

\section{Research Methodology}

This study followed the analytic descriptive methodology that is based on the research and study of the new concept of social control and its main patterns from different angels and qualitatively express them through studying the literature review of the problem and discussing it, which leads to control the use of network communities by individuals in a way that enables them to behave in a conscious responsible manner.

\section{Research Results and Discussion}

After reviewing the preceding studies and based on the importance of this current study, its important topic, its empirical context and the question it is trying to answer, the study reached the following results:

\subsection{The Answer to the First Question: What is the new social control?}

The full detailed answer of this question would need several chapters. Social Control is a guided and purposeful process based on the good nature of the human being; for individuals to achieve their goals in accordance with their societies' norms without causing any harm to other individuals or societal institutions. New Social Control, however, is related to individuals' use of internet and all its services in all forms, and is based on their presence within these network communities.

Based on what has been mentioned in the literature review, we can define the new social control as the collective practices and behaviors of a society upon its members to educate them and organize their behavior to be consistent with the prevailing norms within this society, through a number of methods so that their behavior would meet the society's expectations. Such methods aim at the sustainability of the society and its development while preserving its structure; since societies continue to exist based on their ability to re-organize themselves when their individual members tend to acquire new behaviors that would drag them away from their old ones because of new necessities.

In other words, new social controls are behavioral patterns followed when using new technology; such as, using it for electronic exchange of information, electronic participation in network communities or buying and selling goods via internet. Accordingly, new social control aims at reaching individuals who use the internet frequently in an effective and responsible manner without causing any harm for themselves or for others following the society common practices and norms in compliance with laws and regulations within this society.

The new social control in network communities is like social control in local communities in many aspects, even if it is different in its means and methods. In other words, social control in network communities entails all practices of the society upon its members to educate them and organize their behavior when using any online application or website, so that their behavior would be consistent with the prevailing standards within local communities, without causing any harm - by any means - to others, whether individuals or local communities. Such practices aim at satisfying individuals' needs and protecting them within the social context they belong to.

\subsection{The Answer to the Second Question: What is the Methods of this New Social Control?}

When we look at network communities, we see that they have means of regulation, control and rules to ensure privacy and confidentiality; and they have degrees of prevention and blocking of what the organizers of these communities believe is a breach of ethics or a violation of the privacy of others; individuals in these communities themselves may engage in such blocking or reporting inappropriate and unacceptable comments or materials.

However, these methods that aim at achieving social control are various and very complex; for practices that control the behavior of individuals and work as forces that oblige individuals to comply with social norms vary greatly since each human society has its own controlling methods that organize the individuals' lives and control their behaviors to achieve social control; such as, laws, common practices, customs and traditions. The methods 
of social control differ in their importance within different societies and in different time and place. In some societies, individuals' methods come first and then laws follow in the second place. In other societies, the opposite is the case.

Despite the differences in the name of social control methods and their classifications, there is almost a consensus about the importance of such methods. The social system is a natural product of the effectiveness of social control methods. And since the new social control in network communities is like social control in local communities in many aspects, even if it is different in its means and methods, new social control methods can be categorized into two main sets:

\subsection{Official Methods of Social Control}

The type of methods established by society to impose a kind of purposeful control upon its members; such as, rules, regulations, guidelines or instructions that are formulated as regulatory legislations to be committed by all institutions and to be followed when drafting societal, political, educational and economic laws. Such as official methods are set by authorities, which have the right to charge any violators.

\subsection{Non-official Methods of Social Control}

Individuals' adherence to social norms and values through the process of socialization; where the community values of individuals are products of informal social control, which is implicitly practiced by society through specific traditions, norms and customs. In general, individuals absorb their community's values, whether consciously or unconsciously. Informal penalties include shame, ridicule, sarcasm, criticism and disapproval, which can lead the individual to move away from societal norms which are prevailed in their community. In extreme cases, penalties may include social discrimination and exclusion.

As for the different social control institutions in network communities, whether formal or informal ones, we notice two main perspectives:

- The Negative Perspective: Sees the social control as a group of methods that are based on fear and obligation imposed upon individuals from societal powers and the individual has nothing to do but to obey them out of fear. Hence the individual is deprived of their freedom and the basic principles upon which network communities have been established.

$>$ The Positive Perspective: Depends on the individuals' tendency to accept social norms and values because they believe in their credibility. This type of social control is enhanced by a system of rewards that vary from tangible physical ones to social support and acceptance.

\subsection{The Answer to the Third Question: How to Reach a Controlled use of Network Communities?}

To prepare the individuals to achieve their goals for which they have engaged in network communities; and to achieve the most suitable control of any given society, different societal bodies of two directions - integrated in roles and results - emerge. The first direction stems from inside, and second direction is institutional. In the following few lines, we are going to discuss them further:

\subsubsection{First: The Self-direction of Social Control in the Network Communities}

It stems from inside, where the individual internally desires to adhere to societal criteria and values. This direction is achieved through proper introduction of individuals to the digital environment, starting from the early childhood to the teenage and continues if the individual uses network communities. To a great extent, this adherence becomes part and parcel of individuals characters as a result of social upbringing so that they apply certain practices unconsciously in real societies as well as in network communities. In addition to the implantation of self-control of individuals in their patterns of interaction and the emphasis on what has become apparent that the personalities of individuals in the network communities have started to be a real reflection of people. Network communities are not deviant communities as some people used to think in the past, rather they have become of more transparency where their members show their real identities. People now aspire to show a social image that is compatible with the local community in which they live; they totally avoid whatever violates the norms of their local communities. They seek support and social acceptance, and avoid being reported or blocked so they do not breach the traditions and common practices of their local communities. 
The prevailing global trend in the various networks and platforms of social interaction in the network communities is the transformation towards a community that is similar to local communities by showing the real identities of individuals with their real names and the nature of their work and their jobs in an effort to maintain credibility, gain trust from other members, increase security, increase interaction, and reduce the flow of misleading information, or damage.

The criterion of trust is the most important one upon which the interaction in network communities is based; without mutual trust, social interaction is likely to collapse at any moment and probably cease to exist. Irrespective of the fact that it varies greatly according to different customs and traditions of various local communities, serious violations are common among all communities; such as, hate speech against sacred symbols or persons or public or private social institutions or works of hacking or spying or stealing others identities or spreading rumors or insults or harassments or acts of blackmailing, fraud or scamming or pornography. As a result, Twitter has been deleting fake accounts for months, which led to the deletion of more than a million fake accounts on a daily basis within the last few months. In May and June 2018 only, Twitter has deleted 70 million fake accounts.

It should be noted that this global trend does not change the basis on which network communities have started their work that is based on the freedom of expression, even though it began without controls. In fact, network communities are exerting every effort to maintain a pattern of commitment and discipline among their members so that none of them would get any harm. However, we should reconsider how to make balance between freedoms of expression on the one hand and the possibility that this freedom might harm others on the other hand; since freedom of expression has no meaning if people are not feeling safe and secure ${ }^{19}$.

\subsubsection{Second: The Institutional Direction of Social Control in the Network Communities}

It is reflected on the set laws and written regulations by official authorities such as the Electronic Transactions Law and the Cyber Crimes Act, which many countries have been very keen to legislate so as to be followed in local communities as a means of social control of their individuals' behavior in network communities as well.
The British government is preparing to launch a new Internet regulation that will make technology companies responsible for the content on their platforms. This new regulation will be able to penalize companies that fail to remove illegal material within hours ${ }^{20}$. In 2007, Kingdom of Saudi Arabia has decreed the Electronic Transactions Law and the Cyber Crimes Act; such regulations represent a clear example of institutional social control in the network communities, aiming at achieving information security, increasing the use of the computer and its networks and more integration of the network communities; preserving the rights resulting from the use of individuals, in addition to protecting the public interest, ethics and public morals.

Moreover, Kingdom of Saudi Arabia promotes the use of e-transactions at the local and international levels to benefit from them in all areas; such as, commerce, medicine, education, e-government, e-payment and other applications. The kingdom also aims at removing any obstacles that hinder the use of electronic transactions and also reducing cases of abuse and fraud opportunities in electronic transactions and signatures; such as, forgery and stealing. Furthermore, the kingdom seeks to limit the incidence of informational crimes and to identify crimes targeted to the system and to determine penalties for each crime or violation; and to regulate the jurisdiction to follow up and apply the penalties. Thus, society would have a state of social control that covers all details of its members' lives in the network communities that have become an integral part of their daily lives.

Through the combination of both directions social control becomes integrated, which in turn leads to a safe social interaction with integrated elements, in which individuals achieve their various aspirations and desired goals. Parents are reassured that the lives of their children in the network communities are safe and secure. Then individuals would have no doubt that they live in a disciplined community. Though such network communities might witness cases of deviation since they need more time to be more disciplined; yet this is only due to the fact that they are still new communities that have just been recently explored by individuals and communities alike.

Although these network communities are witnessing very fast growth rates, whether in their capacities or their increased numbers of members, individuals still cannot fully understand the idea that these are communities that still in need of social control. Different societies are working 
really hard to emphasize the role of the institutional social control within these network communities. Two attitudes are conflicting: One regards network communities as deviant ones that have no controls whatsoever, where individuals' wrong practices have no consequences; and another regards them as similar as local communities in many aspects, even if they have less tight limits where space, time or geographical boundaries no longer valid. The basic difference between network communities and local communities is the context in which they appear where one appears in real physical settings and the other appears in a virtual context.

\section{Research Conclusions and Recommendations for Future Works}

The study defined the new concept of social control as the collective practices and behaviors of society upon its members to educate them, organize their behaviors or control them in order for their behaviors to be consistent with the prevailing criteria through a group of various methods that lead their behaviors to meet the society expectations, such methods aim at preserving the growth and sustainability of the society, and protecting its structure. The study categorized the methods of new social control into two major categories: First, official methods of social control which are set by the society to enforce a kind of purposeful control of its members through guiding rules and instructions in forms of regulatory legislations to be adhered by all society institutions and individuals alike; Second, non-official methods of social control such as individuals' following of societal criteria and values through the process of socialization. In order to achieve the most suitable control of any given society, different societal bodies of two directions - integrated in roles and results - emerge. The first direction stems from inside, where the individual internally desires to adhere to societal criteria and values. This direction is achieved through proper introduction of individuals to the digital environment, starting from the early childhood to the teenage and continues as long as the individual uses network communities. The second direction is institutional that is reflected on the set laws and written regulations by official authorities such as the Electronic Transactions Law, and the Cyber Crimes Act.
The researcher recommends conducting more studies about social control and their different social dimensions in order to achieve more generalized results since the results of this study are confined to the predetermined goals that it sought to achieve and the questions that it sought to answer. The researcher also recommends more dissemination of laws on the use of network communities as well as more attention to the digital socialization of children and adolescents, thus contributing to the development of active and disciplined members of society in the network communities.

\section{Acknowledgement}

This paper has been presented and discussed during the International Conference on Communication, Management and Information Technology- ICCMIT 2019, Vienna, Austria.

\section{References}

1. The Virtual Community: Homesteading on the Electronic Frontier. 2000. https://www.amazon.com/ Virtual-Community-Homesteading-Electronic-Frontier/ $\mathrm{dp} / 0262681218$

2. Digital in 2018: World's internet users pass the 4 billion mark. 2018, https://wearesocial.com/blog/2018/01/globaldigital-report-2018

3. The Internet Galaxy: Reflections on the internet, business and society. 2003. https://www.researchgate.net/ publication/4929413_The_Internet_Galaxy_Reflections_ on_the_Internt_Business_and_Society

4. Fundamentals of Islamic Education. 1977. https://www. amazon.com/Fundamentals-Islamic-education-AbdulAlim-Shabazz/dp/B0006WYAYY

5. Al Salem, Khaled. Social control and family cohesion. Riyadh: Library of Law and Economics; 2000. p. 1-30.

6. Al Hamed, M, Al Roumy N. Family and Social Control. Riyadh. 2001. p. 1-182.

7. Jaber, SM. Law and Social Controls. Alexandria: Al Maarefa Al Gameaya Publishing House; 1984. p. 89.

8. Al Rashdan A. Educational sociology. Oman: Al Shrouk Publishing House; 1999. p. 192.

9. Gibbs J. Norms, deviance and social control. New York: Elsevier; 1981.

10. Salwa S. Islam and social control. Cairo: Al Tawfik Publishing House; 1985. p. 40.

11. Al Hamed M, Al Roumy N. ipid. 2001. p.188 
12. Kotbkhana I. Encyclopedia of community culture. Riyadh. 2016. p. 278.

13. Carleton E. Ideology and social order. New York: Routledge; 2015. p.12-32.

14. Goode E. Krohn M, Lane J. Social control and self-control. 2015. https://doi.org/10.1002/9781118513217.ch18

15. van Kokswijk J. Social control in online society: Advantages of self-regulation on the internet. International Conference on Cyberworlds, Singapore; 2010. p. 239-46. https://doi. org/10.1109/CW.2010.44

16. Stranger N, Alnaghaimshi N, Pearsor E. How do Saudi Youth engage with social media? Monday Journal. 2017; 22(15). https://doi.org/10.5210/fm.v22i5.7102
17. Abdullah A. Digital upbringing: Social networks as a model - A study on a sample of parents of adolescents in Jeddah. International Conference of Social Studies; Sharjah. 2018. p. 17-34.

18. Ali Mohamed R. Internet and the techno-social systems. Beirut: Arab Union Studies Center; 2008. p. 91.

19. Twitter is sweeping out fake accounts like never before putting user growth at risk. The Washington Post. 2008.

20. Alex W. The UK Government is planning to set up a regulator for the Internet. 2008. 